\title{
The impact of the COVID-19 lockdown on disordered eating behaviors in youths with type 1 diabetes: Analysis of cross-sectional survey data.
}

Alda Troncone ( $\square$ alda.troncone@unicampania.it )

University of Campania "Luigi Vanvitelli"

Antonietta Chianese

Univerisity of Campania "Luigi Vanvitelli"

Angela Zanfardino

Univerisity of Campania "Luigi Vanvitelli"

Crescenzo Cascella

Univerisity of Campania "Luigi Vanvitelli"

Alessia Piscopo

Univerisity of Campania "Luigi Vanvitelli"

Anna Borriello

Univerisity of Campania "Luigi Vanvitelli"

Serena Rollato

Univerisity of Campania "Luigi Vanvitelli"

Francesca Casaburo

Univerisity of Campania "Luigi Vanvitelli"

Veronica Testa

Univerisity of Campania "Luigi Vanvitelli"

Dario lafusco

Univerisity of Campania "Luigi Vanvitelli"

\section{Research Article}

Keywords: type 1 diabetes, children, adolescents, disordered eating behaviors, COVID-19

Posted Date: August 2nd, 2020

DOI: https://doi.org/10.21203/rs.3.rs-50466/v1

License: (c) (7) This work is licensed under a Creative Commons Attribution 4.0 International License. Read Full License 


\section{Abstract}

Background: Recent research indicates that patients with type 1 diabetes (T1D) are at higher risk for disordered eating behaviors (DEBs) than their peers without diabetes. The present study aimed at examining the impact of the COVID-19 lockdown on DEBs in a sample of Italian children and adolescents with T1D and in matched-pair healthy controls.

Methods: 138 children and adolescents with T1D (aged 8.01-19.11 years, 65 boys) attending a Southern Italian diabetic service and 276 age- and gendermatched healthy peers voluntarily completed a cross-sectional online survey of eating behaviors (ChEAT and Eat-26), anthropometric characteristics, and clinical characteristics.

Results: $8.69 \%(\mathrm{~N}=12)$ of participants with T1D and $13.4 \%(\mathrm{~N}=37)$ of controls had ChEAT/EAT-26 scores indicating presence of DEBs, with no differences between patients-whether children (total ChEAT score $\mathrm{F}(1,157)=.104, p=.748$ ) or adolescents (total EAT-26 score $\mathrm{F}(1,255)=.135, p=.731$ ) - and healthy peers. zBMI values were lower than those measured in the latest diabetes visit $(p<.0001)$, while HbA1c values remained unchanged $(p=.110)$. In both groups, adolescents had lower Oral Control scores than children (T1D: $F(1,138)=20.411, p<.0001, \eta^{2}=.132$, controls: $F(1,276)=18.271, p<.0001, \eta^{2}=.063$ ); additionally, gender (female) and age were found to be significant predictors of several ChEAT/EAT-26 scores.

Discussion: Psychological conditions in relation to DEB symptoms of children and adolescents with T1D were not aggravated by lockdown conditions. Results indicated DEBs as more of a female adolescent developmental issue rather than as a result of the challenges of living with a chronic illness aggravated by outbreak. Possible effects of parental pressure on their children's eating behaviors in the context of home confinement and of using a nondiabetes-specific measure to assess DEBs are discussed.

\section{Background}

In response to the coronavirus disease 2019 (COVID-19) outbreak and to contain the spread of the infection, a temporary lockdown was announced by the Italian Prime Minister on March 9, 2020. Complete restriction on all international and domestic travel, social isolation, a nationwide school closure, and suspension of all non-essential services were established until May 3.

Quarantine has often been associated with several negative emotional consequences, decline in work performance, poor concentration, confusion, numbness, grief, insomnia, low mood that can reach depressive symptoms, psychological distress, and post traumatic/acute stress symptoms, along with long-term results such as alcohol abuse, dependency symptoms, and avoidance behaviors [1,2].

During the time of the COVID-19 epidemic, studies conducted in China suggested that Chinese people experienced significant psychological distress [3]. During the level I emergency, moderate and high levels of psychological symptoms were observed in more than $70 \%$ of regular citizens [4]. Chinese people who were examined before and after the declaration of COVID-19 also showed more negative emotions (i.e., depression, anxiety, and indignation), fewer positive emotions, and less life satisfaction [5]. The outbreak was determined to affect the mental health of Chinese college students too, who consequentially showed symptoms of anxiety [6].

In the time of COVID-19, the psychological impact on individuals suffering from type 1 diabetes (T1D) - who were already described by researchers as individuals needing particular attention [7-10]-can be critical for several reasons.

First, individuals with T1D might be more strongly influenced by the emotional responses related to COVID-19 as they suffer from a chronic disease. According to data from the general population in China, those with poor self-rated health status and a history of chronic illnesses experienced a significant psychological impact from the outbreak along with higher levels of stress, anxiety, and depression [11].

Second, people with T1D specifically are considered to be at an increased risk in general for psychological difficulties, such as behavioral disorders, anxiety symptoms, and psychological distress [12-15]. They are also at risk for disordered eating behaviors (DEBs)-i.e., mild to extreme dieting behavior, including caloric restriction, skipping meals, binge eating attacks, unhealthy behaviors for weight control, and/or use of insulin restriction for intentional calorie purging $[16,17]$; these behaviors are reported more in youths with T1D compared to healthy peers [18-22] and are significantly associated with poorer glycemic control [23]. It has been assumed that specific elements of diabetes and its treatment (i.e., dietary restrictions, recurring weight variation, focus and attention to the body, food preoccupation, continuous attention to food intake, meal planning, counting carbohydrates, etc.) may generally facilitate the development of DEBs $[24,25]$.

Third, infection-containment measures are particularly traumatizing for children and adolescents: prolonged school closure, the lack of outdoor activities and interaction with friends and classmates, fear of infection, boredom, frustration, and lack of personal space at home were found to have a significant negative effect on children's physical and mental health $[1,26]$. The interaction between major lifestyle changes and the psychosocial stress caused by home confinement could create a vicious cycle, further aggravating the detrimental effects of the quarantine on youths' physical and mental health [11]

As a result, in the time of COVID-19 children and adolescents with T1D require particular attention, because their psychological conditions might be naturally aggravated during a pandemic.

To date, several studies have been conducted on the medical aspects of COVID-19 highlighting that the present outbreak can worsen the condition of those with pre-existing mental health conditions and of those who are already vulnerable to psychosocial stressors [27, 28]. However, little research-both in general and in high-risk groups for psychological symptoms (such as T1D youths)-has explored the psychological impact of this disease. 
In light of this, the present study aims to investigate the psychological impact that this lockdown may have on children and adolescents with T1D. Specifically, the study was designed to: (1) evaluate the presence of DEB symptoms in a sample of Italian children and adolescents with T1D and in a sample of matchedpair healthy controls; and (2) to analyze the relationship between DEBs and sociodemographic, anthropometric, and clinical diabetes-related factors. It should be expected that, with limited free space to exercise, limited resources to implement a healthy lifestyle, difficulties in obtaining physician's guidance, the increase of free time, and the reduction of school demands, the need to be busy in pleasant activities would have the potential to increase the focus on food in youths with T1D and their use of it to mitigate subjective stress.

\section{Methods}

\section{Participants and study procedure}

The participants were recruited from among the patients attending a southern Italy pediatric diabetes center from April 1-30, 2020. To be included in the study, patients had to satisfy the following inclusion criteria: aged 8-19 years; T1D diagnosed at least one year prior to study enrollment; at least 6 months of using intermittently scanned continuous glycemic monitoring (CGM) device (Abbott FreeStyle Libre® Glucose Monitoring System, which was chosen as one of the CGM systems most used by patients attending the service); and absence of any significant developmental, cognitive, psychological, or medical conditions. Of the 751 patients examined in the electronic medical records/database, 305 were determined to be eligible.

The parents of these patients were contacted via phone in order to further screen for eligibility as well as to invite them to participate to the study. Investigators called up to 3 times if subjects were not reached. During the phone call, parents were given a brief explanation of the study's purposes and were asked to confirm that their son/daughter was currently using the FreeStyle Libre sensor. The parents whose child was confirmed as eligible and who agreed to participate in the study were sent a text message, which gave them access to fill in the informed consent form and included a link to allow their children to complete a web-based questionnaire (Google form).

In a similar procedure to that described for youth with T1D, control participants were recruited among medical and non-medical friends of the research team in the same period and the same geographic area. All children with known physical or psychological handicaps (confirmed by parents during the phone call) were excluded from the control group. From the healthy controls, participants were selected who best matched to the clinical group for age and gender (two control participants for each T1D case).

The study was approved by the local ethics committee and was conducted according to the principles of the Helsinki Declaration II.

\section{Measures}

Sociodemographic and clinical data. A brief survey was designed ad hoc for the study to record participants' demographic and clinical data, including age, gender, height, weight, and (absence of) significant medical or psychological conditions (all participants). Additionally, this survey asked for mean blood glucose values as collected and calculated by CGM in the 2- and 4-week period (15 and 30 days) preceding the study.

Patients' duration of illness and the HbA1c values of their latest clinical visit (dated back to April 2019-March 2020) were collected from the electronic medical records. Since evidence suggests that at least 14 days of CGM data provide a good estimation of HbA1c values [29], a current $\mathrm{HbA1c}$ values estimation (only for participants with T1D) was obtained from the CGM mean glucose values of the one-month period (the previous 4 weeks). Estimated HbA1c was calculated according to ADAG (A1C-derived average glucose) Study Group data [30].

Weight status. BMI was used as a measure of actual weight status. Given that this index varies based on age and gender in children and adolescents, the BMI z-score was calculated for each participant based on gender, age, weight, and height, according to the Center for Disease Control (CDC) growth curve tables [31].

DEBs. The Eating Attitudes Test-26 (EAT-26) is one of the most widely-used standardized self-report screening measures to assess symptoms of eating problems and eating disorder risk in general [32]. It is a 26-item abbreviated version of EAT [33], with items rated on a 6-point scale (always, very often, often, sometimes, rarely, and never). It includes three subscales: Dieting (e.g., "Particularly avoid food with a high carbohydrate content"); Bulimia and Food Preoccupation ("Have gone on eating binges where I feel that I may not be able to stop"); and Oral Control ("Avoid eating when I am hungry"). The total score is scored as the sum of all items.

As suggested by Garner et al. [32] and consistent with previous research [34, 35], the EAT-26 total score cutoff of $\geq 20$ indicates greater presence of symptoms associated with eating problems, to a level warranting attention and further investigation.

To examine eating attitudes and behaviors among children in grades 3-8 a modification of the EAT-26 for children-the Children Eating Attitudes Test (ChEAT) $[36,37]-$ was used. ChEAT is essentially the EAT with simplified language. Like EAT-26, it is comprised of 26 items scored on a six-point Likert scale, with higher scores indicating greater severity; a score of 20 has been used as a cutoff to identify disturbed eaters [36].

Much evidence has shown that ChEAT [36-40] and EAT-26 [32, 41-43] are reliable and valid psychometric tools to internationally assess abnormal eating attitudes. For the present study, a validated Italian version both the EAT-26 [35] and ChEAT [40] were used.

\section{Statistical Analysis}

To assess the homogeneity of the scale, the Cronbach's alpha (a) was computed. Chi-square testing was used to test frequencies between groups, and Student's $t$-tests were used to compare the means of the sociodemographic and clinical variables between the two groups (i.e., patients and control). Two-way 
ANOVA was used to examine the main effects of gender and group (T1D vs. controls), as well as gender $\times$ group interaction on DEBs (ChEAT and EAT-26 scores).

Hierarchical multiple regression analyses were conducted to evaluate the relationship between DEB and variables of interest (age, gender, zBMI, duration of illness, glycemic control). The ChEAT/EAT-26 scores (total and subscales) were the dependent variable. To analyze whether this relationship interacted with illness, regression analyses were performed separately for participants with T1D and for controls. Tolerance values of $>0.1$ were considered acceptable to exclude multicollinearity [41].

All analyses were carried out with the raw scores. Results were considered significant at alpha $=0.05$ for a two-sided test. The statistical analysis was conducted with Statistical Package for the Social Sciences (SPSS) version 21.0 for Macintosh.

\section{Results}

\section{Sample characteristics}

Out of 305 parents of children with T1D who were approached, 153 were excluded ( $\mathrm{N}=26$ could not be reached by phone due to incorrect phone numbers or lack of answers, $\mathrm{N}=127$ patients had not been using the FreeStyle Libre sensor). In addition, $\mathrm{N}=7$ parents were unwilling to participate, due to general worries that their children would undergo psychological evaluation, temporary family problems, or reluctance/difficulty in using mobile phones and web-based information; $\mathrm{N}=7$ children refused to participate, due to lack of interest or because they were completing homework or busy with other activities.

In terms of the healthy control sample, of 310 parents approached, $\mathrm{N}=5$ could not be reached (due to lack of answers), and $\mathrm{N}=5$ parents refused to participate (out of perplexity regarding the possibility of their children undergoing psychological evaluation). $\mathrm{N}=2$ were excluded because a second analysis revealed that they did not meet the inclusion criteria (i.e., they suffered from chronic illnesses). Selections were made from the $\mathrm{N}=298 \mathrm{healthy}$ participants enrolled in order to achieve the best matching control peers (for age and gender).

In the end, the study samples consisted of 138 children and adolescents with T1D (65 m, $73 \mathrm{f}$ ) and 276 healthy peers (112m, 164f). The demographic and clinical information of children with T1D are shown in Table 1.

Table 1. Demographic and clinical data of participants with T1D and controls

\begin{tabular}{|c|c|c|c|}
\hline & T1D & Healthy controls & \\
\hline & $N=138$ & $N=276$ & \\
\hline & $M(S D)$ & $M(S D)$ & $p$ \\
\hline Sample size $(N)$ & 138 & 276 & \\
\hline Gender $(N)$ (male/female) & $65 / 73$ & $112 / 164$ & .206 \\
\hline Age (years) & 13.67(3.21) (range 8.01-19.11) & $13.78(3.01)(8-19.11)$ & .725 \\
\hline Diabetes duration (years) & $5.98(3.22)$ & - & - \\
\hline HbA1c (\%) estimation 15-30 days / latest visit & $8.45(1.44)-8.42(1.33) / 8.24(1.2) \dagger$ & - & - \\
\hline z-BMI (current)/latest visit & $.53(1.01) / .89(1.03) \neq$ & $.42(.96) /-$ & .353 \\
\hline
\end{tabular}

Data are presented as mean values and standard deviations unless otherwise stated.

Abbreviations: T1D= type 1 diabetes; $\mathrm{N}=$ number of subjects; $\mathrm{z}-\mathrm{BMI}=$ standardized body mass index

tCompared with HbA1c as measured in latest visit (estimation 15 days $t(137)=-1.723, p=.087 ; 30$ days $t(137)=-1.609, p=.110$ )

¥ Compared with zBMI as measured in latest visit $(\mathrm{t}(137)=8.102, \mathrm{p}<.0001)$

No statistically significant differences were found between the children with T1D and the control group in terms of gender $\left(X^{2}=1.599, p=.206\right)$, age $(\mathrm{t}(412)=-.352, p=.725)$, or zBMI $(\mathrm{t}(412)=1.110, p=.267)$.

In participants with T1D, the current mean zBMI of .53(1.01) was significantly lower than that measured at the latest visit $(\mathrm{t}(137)=8.102, p<.0001)$, while mean $\mathrm{HbA} 1 \mathrm{c}$ values $(15 / 30$ days estimation) of $8.42 \%(68 \mathrm{mmol} / \mathrm{mol})$ did not differ from those measured at the latest visit $(15 \mathrm{days} \mathrm{t}(137)=-1.723, p=.087 ; 30 \mathrm{days}$ $\mathrm{t}(137)=-1.609, p=.110)$. Factorial ANOVA confirmed that compared to healthy controls, participants with T1D did not differ in $z B M I$ values $(F(1,414)=.869$, $p=.353)$. Additionally, factorial ANOVA revealed no significant main effect of gender $(F(1,414)=496, p=.482)$ or interaction $($ gender $\times$ disease $)(F(1,414)=1.018$, $p=.313$ ) on zBMI values. 


\section{DEBs in DT1 and controls}

The mean score for each ChEAT/EAT-26 subscale by group can be seen in Table 2 .

Table 2. Ch-EAT/EAT-26 Cronbach's alpha coefficients, mean scores in total sample, children and adolescents with and without T1D. Frequency of DEBs as measured by Ch-EAT/EAT-26 in total sample, children and adolescents with and without T1D. Comparisons of means and frequencies on the basis of illness and age.

\begin{tabular}{|c|c|c|c|c|c|c|c|c|c|c|c|}
\hline & & \multicolumn{3}{|c|}{ Total sample } & \multicolumn{3}{|c|}{ Children ( $\leq 13 y)$} & \multicolumn{3}{|c|}{ Adolescents (>13y) } & \multirow{3}{*}{$\begin{array}{l}\text { T1D } \\
\text { Children v } \\
\text { Adolescer }\end{array}$} \\
\hline & & & & $\begin{array}{l}\text { T1D } \\
\text { ys. }\end{array}$ & $\mathrm{T} 1 \mathrm{D}$ & Controls & $\begin{array}{l}\text { T1D } \\
\text { vs. }\end{array}$ & T1D & Controls & $\begin{array}{l}\text { T1D } \\
\text { vs. }\end{array}$ & \\
\hline & & $N=138$ & $N=276$ & Ctrl & $\mathrm{N}=51$ & $N=107$ & Ctrl & $N=87$ & $N=169$ & Ctrl & \\
\hline & $a$ & $M(S D)$ & $M(S D)$ & $p$ & $M(S D)$ & $M(S D)$ & $p$ & $M(S D)$ & & $p$ & $p$ \\
\hline \multicolumn{12}{|l|}{$\begin{array}{l}\text { Ch- } \\
\text { EAT/EAT- } \\
26\end{array}$} \\
\hline $\begin{array}{l}\text { Score } \geq \\
20 \%(N)\end{array}$ & & $8.69(12)$ & $13.4(37)$ & .162 & $3.9(2)$ & $14.9(16)$ & .056 & 11.49 (10) & $12.4(21)$ & .83 & .128 \\
\hline Dieting & $.695 / .868$ & $6.38(5.53)$ & $5.8(6.88)$ & .132 & $5.20(3.91)$ & $4.87(5.19)$ & .394 & 7.07(6.21) & 6.38(7.72) & .225 & .061 \\
\hline $\begin{array}{l}\text { Oral } \\
\text { control }\end{array}$ & $\begin{array}{l}.656 / \\
.698\end{array}$ & $2.23(2.55)$ & 2.67(3.59) & .358 & $3.45(2.89)$ & $3.79(3.93)$ & .694 & $1.52(2.03)$ & $1.96(3.18)$ & .413 & $<.0001$ \\
\hline $\begin{array}{l}\text { Bulimia } \\
\text { food } \\
\text { preocc. }\end{array}$ & $.529 / .787$ & $1.14(1.86)$ & $1.41(2.58)$ & .427 & $1.14(1.39)$ & $1.21(1.96)$ & .840 & $1.14(2.1)$ & $1.54(2.9)$ & .410 & .913 \\
\hline $\begin{array}{l}\text { Total } \\
\text { score }\end{array}$ & $.696 / .909$ & $9.75(7.71)$ & 9.88(10.79) & .636 & $9.78(5.27)$ & $9.87(7.59)$ & .748 & $9.72(8.87)$ & $9.89(12.41)$ & .731 & .916 \\
\hline
\end{tabular}

Abbreviations: T1D= type 1 diabetes; Ctrl= control; Bulimia food preocc.= Bulimia and Food Preoccupation

The Cronbach's alpha reliability coefficient for the EAT-26 and the ChEAT (total scores) showed satisfactory levels (Table 2).

Total sample. According to the ChEAT/EAT-26 scores, $8.69 \%(\mathrm{~N}=12)$ of participants with T1D and 13.4\% ( $\mathrm{N}=37)$ of controls had values of 20 or more, indicating presence of DEBs. No significant differences in DEB frequency were seen between patients and healthy controls $\left(X^{2}=.1956, p=.162\right)$, between children $\left(X^{2}=3.66, p=.055\right)$ and adolescents with T1D $\left(X^{2}=.134, p=.714\right)$ compared to matched healthy peers, between children with T1D and adolescents with $\operatorname{T1D}\left(X^{2}=2.322, p=.128\right)$, and between children and adolescents of control $\left(X^{2}=.048, p=.827\right)$.

Two-way ANOVA (disease $\times$ gender) indicated that participants with T1D did not score differently from healthy controls in any ChEAT/EAT-26 scales (Dieting $\mathrm{F}(1,414)=2.282, p=.132$; Oral control $\mathrm{F}(1,414)=.848, p=.358$; Bulimia and Food Preoccupation $\mathrm{F}(1,414)=.631, p=.427$; Total score $\mathrm{F}(1,414)=.224, p=.636)$.

There were main effects of gender for all of the ChEAT/EAT-26 subscales (Dieting $F(1,414)=27.207, p=.000, \eta^{2}=.062 ;$ Oral Control $F(1,414)=3.987, p=.047, \eta^{2}$ $=.010$; Bulimia and Food Preoccupation $\mathrm{F}(1,414)=11.002, p=.001, \eta^{2}=.026$; Total score $\mathrm{F}(1,414)=24.118, p<.0001$, $\left.\eta^{2}=.056\right)$, indicating that girls had significantly higher ChEAT/EAT-26 scores than boys.

There was also an interaction between disease and gender for two ChEAT/EAT-26 subscales and the Total score $\left(\right.$ Dieting $F(1,414)=4.954, p=.027, \eta^{2}=.012$; Oral Control $\mathrm{F}(1,414)=3.963, p=.047, \eta^{2}=.010$; Total score $\left.\mathrm{F}(1,414)=5.621, p=.018, \eta^{2}=.014\right)$, with healthy boys having lower EAT scores than other groups. No interaction effects were found for Bulimia scores $(F(1,414)=.888, p=.347)$.

Children. In a comparison of children ( $\leq 13 y)$ with T1D to matched healthy controls, no significant differences were found in the ChEAT Total score ( $F(1$, $157)=.104, p=.748$ ) or in subscale scores (Dieting $\mathrm{F}(1,157)=.732, p=.394$; Oral Control $\mathrm{F}(1,157)=.155, p=.694$; Bulimia and Food Preoccupation $\mathrm{F}(1,157)=.041$, $p=.840)$.

A main effect of gender was found for the ChEAT Total score $\left(F(1,157)=5.811, p=.017, \eta^{2}=.036\right)$ and the Dieting $\left(F(1,157)=6.532, p=.012, \eta^{2}=.041\right)$ subscale -with girls having higher scores than boys-but not for Oral control $(F(1,157)=1.902, p=.170)$ or Bulimia and Food Preoccupation $(F(1,157)=.125, p=.725)$, for which the scores did not differ between boys and girls.

There was an interaction effect of disease $\times$ gender only for Dieting scores $\left(F(1,414)=4.356, p=.039, \eta^{2}=.028\right)$, indicating that healthy boys had the lowest ChEAT scores compared to other groups. No interaction effects were found for Oral Control $(F(1,157)=.263, p=.609)$, Bulimia and Food Preoccupation 
$(\mathrm{F}(1,157)=.111, p=.740)$, and Total score $(\mathrm{F}(1,157)=3.259, p=.073)$.

Adolescents. In a comparison of adolescents (>13y) with matched healthy controls, no significant differences were found in the EAT-26 Total score ( $F(1$, $255)=.135, p=.731$ ) or in its subscales (Dieting $F(1,255)=1.418, p=.225$; Oral Control $F(1,255)=.674, p=.413$; Bulimia and Food Preoccupation $F(1,255)=.680$, $p=.410)$.

For all comparisons, ANOVA indicated a significant main effect of gender on the EAT-26 Total score and subscale scores $($ Total score $F(1,255)=18.421$, $p<.0001, \eta^{2}=.068$; Dieting $\mathrm{F}(1,255)=21.157, p=.000, \eta^{2}=.077$; Bulimia and Food preoccupation $\left.\mathrm{F}(1,255)=16.360, p<.0001, \eta^{2}=.061\right)$ except for the Oral Control subscale $(\mathrm{F}(1,255)=2.382, p=.124)$.

Interaction effects of disease $\times$ gender were only found for the Oral Control subscale $\left(F(1,255)=5.703, p=.018, \eta^{2}=.022\right)$, indicating that healthy girls had the highest EAT-26 scores compared to other groups. No significant interaction (gender $\times$ disease) effects were found for Total score $(F(1,255)=3.203, p=.075)$, Dieting $F(1,255)=2.180, p=.141)$, or Bulimia and Food Preoccupation $(F(1,255)=.939, p=.333)$ scores.

Children vs. adolescents. In a comparison of children with T1D and adolescents with T1D, no significant differences were found in the ChEAT Total score $(\mathrm{F}(1,138)=.011, p=.916)$ or for two subscales (Dieting $\mathrm{F}(1,138)=3.569, p=.061$; Bulimia and Food Preoccupation $\mathrm{F}(1,138)=.012, p=.913)$. A main effect of age was found for the Oral Control subscale $\left(F(1,138)=20.411, p<.0001, \eta^{2}=.132\right)$, indicating that adolescents had lower scores than children.

No main effect of gender and no interaction effects (gender $\times$ age) were found for the ChEAT/EAT-26 Total score (gender $F(1,137)=2.497, p=.116$; interaction $\mathrm{F}(1,137)=1.139, \mathrm{p}=.288$ ) or for Dieting (gender $\mathrm{F}(1,137)=2.854, p=.093$; interaction $\mathrm{F}(1,137)=1.693, \mathrm{p}=.195)$, Oral control (gender $\mathrm{F}(1,138)=.070, p=.792$; interaction $\mathrm{F}(1,138)=1.013, p=.316$ ), or Bulimia and Food Preoccupation (gender $\mathrm{F}(1,138)=1.651, p=.201$, interaction $\mathrm{F}(1,138)=3.774, p=.054)$ scores.

In a comparison of healthy children with adolescents, no significant differences were found in the ChEAT/EAT-26 Total score $(F(1,276)=.055, p=.815)$ or in two subscales (Dieting $\mathrm{F}(1,276)=2.845, p=.093$; Bulimia and Food Preoccupation $(\mathrm{F}(1,276)=.334, p=.564)$. A main effect of age was found in the Oral Control subscale score $\left(F(1,276)=18.271, p<.0001, \eta^{2}=.063\right)$, indicating that adolescents had lower scores than children.

A main effect of gender was found for Total score $\left(F(1,276)=17.825, p<.000, \eta^{2}=.093\right)$, Dieting $\left(F(1,276)=32.362, p<.0001, \eta^{2}=.106\right)$, Oral Control $\left(F(1,276)=9.254, p=.003, \eta^{2}=.033\right)$, and Bulimia and Food Preoccupation $\left(F(1,276)=7.263, p=.007, \eta^{2}=.026\right)$, indicating that girls had higher scores than boys No interaction effects were found for the ChEAT/EAT-26 Total score $(F(1,276)=2.277, p=.132)$, Dieting $(F(1,276)=1.345, p=.247)$, or Oral Control $(F(1,276)=.109$, $p=.741)$. An age $\times$ gender interaction was only found in Bulimia and Food Preoccupation $\left(F(1,276)=7.370, p=.007, \eta^{2}=.026\right)$, indicating that adolescent girls had the highest scores of all groups.

\section{Predictors of DEBs}

Table 3 presents the results of a hierarchical regression predicting DEBs (ChEAT/EAT-26 scores) in participants with T1D and in healthy controls.

Table 3. Summary of linear regression analyses of variables predicting DEBs (ChEAT/EAT-26 subscales and total scores) in participants with T1D and controls 


\begin{tabular}{|c|c|c|c|c|c|c|c|c|c|c|}
\hline \multirow[b]{2}{*}{ Variables } & \multicolumn{5}{|c|}{ T1D (N=138) } & \multicolumn{5}{|c|}{ Controls $(\mathrm{N}=276)$} \\
\hline & B & SE B & $\beta$ & $p$ & Collinearity & B & SE B & $\beta$ & $p$ & Collinearity \\
\hline Ch-EAT/EAT-26 & & & & & tolerance & & & & & tolerance \\
\hline \multicolumn{11}{|l|}{ Dieting } \\
\hline \multicolumn{11}{|l|}{ Step 1} \\
\hline Age & .290 & .144 & .168 & .046 & .999 & .325 & .129 & .142 & .012 & .991 \\
\hline \multirow[t]{2}{*}{ Gender } & 1.882 & .923 & .170 & .043 & .999 & .4 .623 & .789 & .331 & $<.0001$ & .991 \\
\hline & \multicolumn{3}{|l|}{$\mathrm{R}^{2}=.059$} & \multicolumn{2}{|l|}{.017} & \multicolumn{3}{|l|}{$\mathrm{R}^{2}=.138$} & \multicolumn{2}{|l|}{$<.0001$} \\
\hline \multicolumn{11}{|l|}{ Step 2} \\
\hline Age & .368 & .152 & .213 & .017 & .798 & .302 & .129 & .132 & .020 & .982 \\
\hline Gender & 2.156 & .884 & .195 & .016 & .974 & 4.764 & .790 & .341 & $<.0001$ & .981 \\
\hline z-BMI & 1.562 & .440 & .283 & .001 & .977 & .729 & .404 & .102 & .073 & .983 \\
\hline Duration of illness & -.311 & .156 & -.181 & .048 & .759 & & & & & \\
\hline \multirow[t]{2}{*}{$\mathrm{HbA1c}$} & -.515 & .337 & -.124 & .129 & .950 & & & & & \\
\hline & \multicolumn{3}{|l|}{$\Delta \mathrm{R}=.118$} & \multicolumn{2}{|l|}{.001} & \multicolumn{2}{|l|}{$\Delta \mathrm{R}=.010$} & & \multicolumn{2}{|l|}{$<.0001$} \\
\hline Total $\mathrm{R}^{2}$ & & .177 & & & & . & .149 & & & \\
\hline \multicolumn{11}{|l|}{ Oral Control } \\
\hline \multicolumn{11}{|l|}{ Step 1} \\
\hline Age & -.285 & .064 & -.359 & $<.0001$ & .999 & -.297 & .069 & -.249 & $<.0001$ & .991 \\
\hline \multirow[t]{2}{*}{ Gender } & .053 & .410 & .010 & .898 & .999 & 1.533 & .422 & .210 & $<.0001$ & .991 \\
\hline & \multicolumn{3}{|l|}{$\mathrm{R}^{2}=.129$} & \multicolumn{2}{|l|}{$<.0001$} & \multicolumn{2}{|l|}{$\mathrm{R}^{2}=.096$} & & \multicolumn{2}{|l|}{$<.0001$} \\
\hline \multicolumn{11}{|l|}{ Step 2} \\
\hline Age & -.259 & .072 & -.326 &.$<.0001$ & .798 & -.271 & .067 & -.227 & $<.0001$ & .982 \\
\hline Gender & .095 & .416 & .019 & .820 & .974 & 1.367 & .413 & .187 & .001 & .981 \\
\hline z-BMI & -.289 & .207 & -.114 & .166 & .977 & -.859 & .211 & -.230 & $<.0001$ & .983 \\
\hline Duration of illness & -.036 & .073 & -.045 & .626 & .759 & & & & & \\
\hline \multirow[t]{2}{*}{$\mathrm{HbA1c}$} & -.034 & .159 & -.018 & .830 & .950 & & & & & \\
\hline & $\Delta R=.016$ & & & .001 & & $\Delta \mathrm{R}=.052$ & & & $<.0001$ & \\
\hline Total $\mathrm{R}^{2}$ & & .144 & & & & & .148 & & & \\
\hline Bulimia and food $p$ & & & & & & & & & & \\
\hline Step 1 & & & & & & & & & & \\
\hline Age & .064 & .049 & .110 & .197 & .999 & .070 & .051 & .082 & .171 & .991 \\
\hline Gender & .569 & .314 & .153 & .072 & .999 & 1.000 & .311 & .191 & 001 & .991 \\
\hline & $\mathrm{R}^{2}=.036$ & & & .081 & & $\mathrm{R}^{2}=.046$ & & & .002 & \\
\hline Step 2 & & & & & & & & & & \\
\hline Age & .093 & .055 & .160 & .094 & .798 & .061 & .051 & .071 & .234 & .982 \\
\hline Gender & & & & & & 1.058 & .311 & .202 & .001 & .981 \\
\hline
\end{tabular}

Page $7 / 12$ 


\begin{tabular}{|c|c|c|c|c|c|c|c|c|c|c|}
\hline z-BMI & .001 & 159 & .001 & .994 & .977 & 298 & .159 & .111 & .063 & .983 \\
\hline Duration of illness & -.068 & .056 & -.118 & .229 & .759 & & & & & \\
\hline \multirow[t]{2}{*}{$\mathrm{HbA} 1 \mathrm{c}$} & -.007 & .122 & -.005 & .061 & .950 & & & & & \\
\hline & $\Delta R=.011$ & & & .258 & & $\Delta \mathrm{R}=.012$ & & & .001 & \\
\hline Total $\mathrm{R}^{2}$ & & .048 & & & & & .058 & & & \\
\hline \multicolumn{11}{|l|}{ Total score } \\
\hline \multicolumn{11}{|l|}{ Step 1} \\
\hline Age & .069 & .204 & .029 & .737 & .999 & .097 & .205 & .027 & .637 & .991 \\
\hline \multirow[t]{2}{*}{ Gender } & 2.504 & 1.307 & .163 & .058 & .999 & 7.156 & 1.259 & .326 & $<.0001$ & 991 \\
\hline & $\mathrm{R}^{2}=.028$ & & & .152 & & $\mathrm{R}^{2}=.109$ & & & $<.0001$ & \\
\hline \multicolumn{11}{|l|}{ Step 2} \\
\hline Age & .202 & .224 & .084 & .369 & .798 & .092 & .207 & .026 & .657 & .982 \\
\hline Gender & 2.882 & 1.296 & .187 & .028 & .974 & 7.189 & 1.267 & .328 & $<.0001$ & .981 \\
\hline z-BMI & 1.274 & .646 & .166 & .050 & .977 & .168 & .649 & .015 & .796 & .983 \\
\hline Duration of illness & -.415 & .228 & -.173 & .072 & .759 & & & & & \\
\hline \multirow[t]{2}{*}{$\mathrm{HbA} 1 \mathrm{c}$} & -.556 & .495 & -.096 & .263 & .950 & & & & & \\
\hline & $\Delta \mathrm{R}=.061$ & & & .030 & & $\Delta R=.000$ & & & $<.0001$ & \\
\hline Total $R^{2}$ & & .089 & & & & & .109 & & & \\
\hline
\end{tabular}

Abbreviations: T1D= type 1 diabetes; $z-B M I=$ standardized body mass index; HbA1c=glycated hemoglobin;

In most cases, the hierarchical regression equations for T1D and control participants was significant (step 1 total score T1D: $\mathrm{F}(2,137)=1.910, p=.152$, controls: $\mathrm{F}(2,275)=16.682, p<.0001$; step 2 total score T1D: $\mathrm{F}(2,137)=2.669, p=.030$, controls: $\mathrm{F}(2,275)=11.106, p<.0001)$, accounting for approximately $5.8-17.7$ of the variance of the majority of ChEAT/EAT-26 subscales (except for Bulimia and Food Preoccupation in T1D scores - step $1 \mathrm{~F}(2,137)=2.555, p=.081$; step 2 $\mathrm{F}(2,137)=1.323, p=.258$ ). Gender (female) was found to be a significant predictor of all ChEAT/EAT-26 subscale scores in controls and of ChEAT/EAT-26 Dieting and Total score in T1D participants; age was associated with the Dieting and Oral Control subscales in both groups. zBMI significantly predicted T1D participants' Dieting scores and control participants' Oral Control scores, while duration of illness was found to predict Dieting score in T1D patients (Table 3).

\section{Discussion}

This study was the first to evaluate the psychological consequences experienced by individuals with T1D approximately one month after the COVID-19 outbreak in Italy and to identify related associated factors. It examined whether the lockdown of Italy-in an attempt to prevent the spread of the virus-might have adversely impacted the eating behavior habits of youths with T1D. Therefore, during the COVID-19 lockdown, a sample of children and adolescents with T1D was compared with gender- and age-matched healthy control individuals.

The present findings suggest that psychological conditions-specifically, DEB symptoms-of children and adolescents with T1D were not aggravated by lockdown conditions. This contradicts the general assumption that "social distancing" and isolation-creating anxiety, sadness, anger, and perception/sense of loneliness-may have a negative psychological impact [1] and even exacerbate eating disorder risks [44], further compromising individuals with psychopathological and eating problems $[27,28,45,46]$. Furthermore, recent evidence from Italian samples [47-51] describe youths with T1D as suffering from DEBs more frequently than healthy peers. In contrast, children and adolescents with T1D evaluated in this study did not show higher DEBs than controls.

These results appear to be consistent with Wang et al.'s study [52] describing no significant differences in mental health problems in quarantined youths (undergraduate students) compared to non-quarantined peers. However, it is possible that other explanations might account for these findings.

First, measuring DEBs using a generic DEB tool adapted for the general population may fail to identify or inaccurately assess certain diabetes-specific eating behaviors, such as insulin omission or reduction, thereby underestimating the prevalence of DEBs among T1D patients [23,53,54]. Second, it could be hypothesized that the present findings could be also explained as a possible effect of parental pressure on their children's eating behaviors. It could be argued that due to home confinement, parents may monitor their children's behavior throughout the day, preventing unhealthy conduct and exhorting them to better meet diabetes rules. In other words, the lockdown may have reduced patients' opportunities to adopt/engage in the unhealthy eating behaviors or weight control practices (e.g., consumption of large quantities of high-fat foods, skipping meals, taking less insulin) that have been frequently observed in teens with diabetes $[55,56]$. Furthermore, it is reasonable to suppose that the lockdown-imposed self-isolation may have reduced/canceled activities and contexts 
typically linked to social situation with peers that usually challenge good diabetes management (e.g., perceiving social pressures to eat inappropriate foods, eating out with friends and seeing them eating and drinking what they want, etc.) and lead to unhealthy behaviors affecting glycemic control [57].

The potential increased parental emphasis on the importance of diabetes control, along with the related pressure to engage in healthy eating behaviors and to take control of their weight, seems to be confirmed by the zBMI values (which were found to be lower than those measured in the latest diabetes visit) and by the $\mathrm{HbA} 1 \mathrm{c}$ values remaining unchanged. It is worth noting that glycemic control-even though higher than the American Diabetes Association's recommended target value of $7.5 \%$ for good metabolic control [58]-is substantially analogous to population data in similar age groups [59, 60].

In terms of DEB predictors, regression analyses revealed the associations between DEBs (i.e., dieting behavior), higher zBMI [17, 19, 61-63], and duration of illness [47], as reported by previous studies on youths with T1D.

In both groups, a key role seemed to be played by gender and age. In line with gender-related prevalence-both in the general adolescent population [64, 65] and in the T1D adolescent population $[63,66,67]$-girls showed higher DEBs than boys (as revealed by the majority of EAT subscales), regardless of illness and of age. In both groups, gender emerged as a significant predictor of general DEB attitudes and dieting behaviors. Similarly, age was found to be a significant predictor of DEB symptoms, revealing that adolescents with and without T1D showed higher levels of dieting behaviors-but lower attitude to oral control-than children (as revealed by adolescents' lower Oral Control mean scores than children).

In line with evidence indicating adolescence as the developmental period during which eating disturbances typically emerge [68] and describing adolescents as frequently engaging in DEBs-both in general [69] and in the T1D population [19-21]-this data confirms that DEBs, especially in terms of dietary restrictions and low oral control, are primarily an adolescent problem. The absence of significant differences between patients and controls in eating problems leads to the consideration of DEBs more as an adolescent developmental issue rather than as a result of the challenges of living with a chronic illness. It is widely recognized that the rapid and dynamic cognitive, developmental, and emotional changes of adolescence (increased independence in decision making, turning to peer group for validation, wishing to be "fit") combine with weight and body image concerns (facing the impact of body changes, giving more importance to body image, putting more focus and energy into searching for acceptance by peers, etc.). These are major issues that adolescents have to face that can favor the adoption of a variety of inappropriate and risk-taking behaviors, such as unhealthy weight control practices and habits [70, 71].

This study has several limitations. The major limitation is that data collection of the data relied on voluntary participation; thus, generalizing to a general T1D population should be done with caution. Additionally, the use of self-reported measures administered online allowed us to overcome the impossibility of conducting a traditional paper survey; however, it may yield imprecise ratings of specific data (e.g., height and weight) and subjective perceptions of behaviors, thoughts, and feelings that might not be sincerely, accurately, or fully revealed. While a web-based survey can be an effective method of gathering data with evident advantages (easy to complete, quick collection of data, potentially lower costs, reduced survey administration overhead), incompatibility with the target environment (e.g., due to the closeness with parents or relatives), computer/smartphone literacy of participants, and program/app defects might negatively impact the quality of data collection [72]. Furthermore, given the cross-sectional nature of the results, longitudinal research is needed to further explore the relationship between DEBs and clinical and sociodemographic variables.

In conclusion, our findings suggest that, as recommended by international guidelines $[12,58,73]$, continuous medical and psychological care is needed in order to periodically monitor physical and psychological conditions, especially during critical developmental phases, as teens age and/or face troubling circumstances such as those imposed by quarantine.

\section{Declarations}

\section{Ethics approval and consent to participate}

The study was approved by the local ethics committee and was conducted according to the principles of the Helsinki Declaration II.

\section{Consent for publication}

Not applicable

\section{Availability of data and materials}

The datasets used and/or analysed during the current study are available from the corresponding author on reasonable request.

\section{Competing interests}

The authors have no conflicts of interest to disclose.

\section{Funding}

This research was supported by the project DiabEat1, which received funding from University of Campania "Luigi Vanvitelli" through the program V:ALERE 2019, funded with D.R. 906 del 4/10/2019, prot. n. 157264, October 172019.

\section{Authors' contributions}

The authors contributed to the study as follow: A.T. designed the study, analyzed the data, and wrote the manuscript. D.I. supervised this work, designed the study, and contributed to the manuscript. A.Z., C.C., A.C., A.P., and A.B. collected data and contributed to data analysis and to writing the manuscript. 


\section{Acknowledgements}

The authors thank the staff of the outpatient clinic at the pediatric diabetes unit "G. Stoppoloni" of the University of Campania "Luigi Vanvitelli" for their help in data collection-in particular Dr. Santino Confetto, Dr. Anna Gentile, and Dr. Mariarca Giorno,-as well as all the patients, parents, and youths who agreed to take part in the investigation.

\section{References}

1. Brooks SK, Webster RK, Smith LE, Woodland L, Wessely S, Greenberg N, et al. The psychological impact of quarantine and how to reduce it: rapid review of the evidence. The Lancet. 2020;395(10227):912-920; doi:10.1016/S0140-6736(20)30460-8

2. Hawryluck L, Gold WL, Robinson S, Pogorski S, Galea S, Styra R. SARS control and psychological effects of quarantine, Toronto, Canada. Emerg Infect Dis. 2004;10(7):1206-1212; doi:10.3201/eid1007.030703

3. Qiu J, Shen B, Zhao M, Wang Z, Xie B, Xu Y. A nationwide survey of psychological distress among Chinese people in the COVID-19 epidemic: implications and policy recommendations. Gen Psychiatr. 2020;33(2):e100213; doi:10.1136/gpsych-2020-100213

4. Tian F, Li H, Tian S, Yang J, Shao J, Tian C. Psychological symptoms of ordinary Chinese citizens based on SCL-90 during the level I emergency response to COVID-19. Psychiatry Res. 2020;288:112992; doi:10.1016/j.psychres.2020.112992

5. Li S, Wang Y, Xue J, Zhao N, Zhu T. The Impact of COVID-19 Epidemic Declaration on Psychological Consequences: A Study on Active Weibo Users. Int J Environ Res Public Health. 2020;17(6):2032; doi:10.3390/ijerph17062032

6. Cao W, Fang Z, Hou G, et al. The psychological impact of the COVID-19 epidemic on college students in China. Psychiatry Res. 2020;287:112934; doi:10.1016/j.psychres.2020.112934

7. Cherubini V, Gohil A, Addala A, et al. Unintended Consequences of COVID-19: Remember General Pediatrics. J Pediatr. 2020. doi:10.1016/j.jpeds.2020.05.004

8. Banerjee M, Chakraborty S, Pal R. Diabetes self-management amid COVID-19 pandemic. Diabetes Metab Syndr. 2020;14(4):351-354; doi:10.1016/j.dsx.2020.04.013

9. Gupta R, Ghosh A, Singh AK, Misra A. Clinical considerations for patients with diabetes in times of COVID-19 epidemic. Diabetes Metab Syndr. 2020;14(3):211-212; doi:10.1016/j.dsx.2020.03.002

10. Tatti P, Tonolo G, Zanfardino A, lafusco D. Is it fair to hope that patients with Type 1 Diabetes (autoimmune) may be spared by the infection of Covid-19? Med Hypotheses. 2020;142:109795; doi:10.1016/j.mehy.2020.109795

11. Wang C, Pan R, Wan X, et al. Immediate Psychological Responses and Associated Factors during the Initial Stage of the 2019 Coronavirus Disease (COVID-19) Epidemic among the General Population in China. Int J Environ Res Public Health. 2020;17(5):1729. Published 2020 Mar 6; doi:10.3390/ijerph17051729

12. Delamater AM, de Wit M, McDarby V, et al. ISPAD Clinical Practice Consensus Guidelines 2018: Psychological care of children and adolescents with type 1 diabetes. Pediatr Diabetes. 2018;19 Suppl 27:237-249; doi:10.1111/pedi.12736

13. Hagger V, Hendrieckx C, Sturt J, Skinner TC, Speight J. Diabetes Distress Among Adolescents with Type 1 Diabetes: a Systematic Review. Curr Diab Rep. 2016;16(1):9; doi:10.1007/s11892-015-0694-2

14. Rechenberg K, Whittemore R, Grey M. Anxiety in Youth With Type 1 Diabetes. J Pediatr Nurs. 2017;32:64-71; doi:10.1016/j.pedn.2016.08.007.

15. Reynolds KA, Helgeson VS. Children with diabetes compared to peers: depressed? Distressed? A meta-analytic review. Ann Behav Med. 2011;42(1):29-41; doi:10.1007/s12160-011-9262-4

16. Neumark-Sztainer D. School-based programs for preventing eating disturbances. J Sch Health. 1996;66(2):64-71; doi:10.1111/j.17461561.1996.tb07912.x

17. Olmsted MP, Colton PA, Daneman D, Rydall AC, Rodin GM. Prediction of the onset of disturbed eating behavior in adolescent girls with type 1 diabetes. Diabetes Care. 2008;31(10):1978-1982; doi:10.2337/dc08-0333

18. Conviser JH, Fisher SD, McColley SA. Are children with chronic illnesses requiring dietary therapy at risk for disordered eating or eating disorders? A systematic review. Int J Eat Disord. 2018;51(3):187-213; doi:10.1002/eat.22831

19. Hanlan ME, Griffith J, Patel N, Jaser SS. Eating Disorders and Disordered Eating in Type 1 Diabetes: Prevalence, Screening, and Treatment Options. Curr Diab Rep. 2013. doi:10.1007/s11892-013-0418-4

20. Jones JM, Lawson ML, Daneman D, Olmsted MP, Rodin G. Eating disorders in adolescent females with and without type 1 diabetes: cross sectional study. BMJ. 2000;320(7249):1563-1566.

21. Pinhas-Hamiel O, Hamiel U, Levy-Shraga Y. Eating disorders in adolescents with type 1 diabetes: Challenges in diagnosis and treatment. World J Diabetes. 2015;6(3):517-526; doi:10.4239/wjd.v6.i3.517

22. Pursey KM, Hart M, Jenkins L, McEvoy M, Smart CE. Screening and identification of disordered eating in people with type 1 diabetes: A systematic review. J Diabetes Complications. 2020;34(4):107522; doi:10.1016/j.jdiacomp.2020.107522

23. Young V, Eiser C, Johnson B, et al. Eating problems in adolescents with Type 1 diabetes: a systematic review with meta-analysis. Diabet Med. 2013;30(2):189-198; doi:10.1111/j.1464-5491.2012.03771.x

24. Goebel-Fabbri AE, Fikkan J, Franko DL, Pearson K, Anderson BJ, Weinger K. Insulin restriction and associated morbidity and mortality in women with type 1 diabetes. Diabetes Care. 2008;31(3):415-419; doi:10.2337/dc07-2026 
25. Larrañaga A, Docet MF, García-Mayor RV. Disordered eating behaviors in type 1 diabetic patients. World J Diabetes. 2011;2(11):189-195; doi:10.4239/wjd.v2.i11.189

26. Sprang G, Silman M. Posttraumatic stress disorder in parents and youth after health-related disasters. Disaster Med Public Health Prep. 2013;7(1):105110. doi:10.1017/dmp.2013.22

27. Fiorillo A, Gorwood P. The consequences of the COVID-19 pandemic on mental health and implications for clinical practice. European Psychiatry. Cambridge University Press; 2020;63(1):e32.

28. Yao H, Chen JH, Xu YF. Patients with mental health disorders in the COVID-19 epidemic. Lancet Psychiatry. 2020;7(4):e2;. doi:10.1016/S22150366(20)30090-0

29. Riddlesworth TD, Beck RW, Gal RL, Connor CG, Bergenstal RM, et al. Optimal Sampling Duration for Continuous Glucose Monitoring to Determine LongTerm Glycemic Control. Diabetes Technol Ther. 2018;20(4):314-316; doi:10.1089/dia.2017.0455

30. Klonoff DC. ADAG study group data links A1C levels with empirically measured blood glucose values - new treatment guidelines will now be needed. J Diabetes Sci Technol. 2014;8(3):439-443; doi:10.1177/1932296814529638

31. Kuczmarski RJ, Ogden CL, Grummer-Strawn LM, Flegal KM, Guo SS, Wei R, et al. CDC growth charts: United States. Adv Data. 2000;(314):1-27..

32. Garner DM, Olmsted MP, Bohr Y, Garfinkel PE. The eating attitudes test: psychometric features and clinical correlates. Psychol Med. 1982;12(4):871-878; doi:10.1017/s0033291700049163

33. Garner DM, Garfinkel PE. The Eating Attitudes Test: an index of the symptoms of anorexia nervosa. Psychol Med. 1979;9(2):273-279; doi:10.1017/s0033291700030762

34. Buddeberg-Fischer B, Bernet R, Sieber M, Schmid J, Buddeberg C. Epidemiology of eating behaviour and weight distribution in 14- to 19-year-old Swiss students. Acta Psychiatr Scand. 1996;93(4):296-304.; doi:10.1111/j.1600-0447.1996.tb10651.x

35. Dotti A, Lazzari R. Validation and reliability of the Italian EAT-26. Eat Weight Disord. 1998;3(4):188-194; doi:10.1007/BF03340009

36. Maloney MJ, McGuire JB, Daniels SR. Reliability testing of a children's version of the Eating Attitude Test. J Am Acad Child Adolesc Psychiatry. 1988;27(5):541-543; doi:10.1097/00004583-198809000-00004

37. Smolak L, Levine MP. Psychometric properties of the Children's Eating Attitudes Test. The International journal of eating disorders. 1994;16(3):275-282; doi:10.1002/1098-108x(199411)16:3<275::aid-eat2260160308>3.0.co;2-u

38. Ambrosi-Randić N, Pokrajac-Bulian A. Psychometric properties of the eating attitudes test and children's eating attitudes test in Croatia. Eat Weight Disord. 2005;10(4): e76-e82; doi: 10.1007/BF03327495.

39. Chiba H, Nagamitsu S, Sakurai R, Mukai T, Shintou H, Koyanagi K, et al. Children's Eating Attitudes Test: Reliability and validation in Japanese adolescents. Eat Behav. 2016;23:120-125; doi:10.1016/j.eatbeh.2016.09.001

40. Laudadio A, Huober N, Di Gianfrancesco R, D'Alessio M. Validazione italiana della scala ChEAT con pre-adolescenti: atteggiamento nei confronti del proprio peso. Psicologia clinica dello sviluppo. 2010;14(2):299-324.

41. Cohen J, Cohen P, West SG, Aiken LS. Applied multiple regression/correlation analysis for the behavioral sciences. Routledge; 2013

42. Lee S, Kwok K, Liau C, Leung T. Screening Chinese patients with eating disorders using the Eating Attitudes Test in Hong Kong. Int J Eat Disord. 2002;32(1):91-97; doi:10.1002/eat.10064

43. Mintz LB, O'Halloran MS. The Eating Attitudes Test: validation with DSM-IV eating disorder criteria. J Pers Assess. 2000;74(3):489-503; doi:10.1207/S15327752JPA7403_11

44. Rivas T, Bersabé R, Jiménez M, Berrocal C. The Eating Attitudes Test (EAT-26): reliability and validity in Spanish female samples. Span J Psychol. 2010;13(2):1044-1056; doi:10.1017/s1138741600002687

45. Rodgers RF, Lombardo C, Cerolini S, Franko DL, Omori M, Fuller-Tyszkiewicz M, et al. The impact of the COVID-19 pandemic on eating disorder risk and symptoms. Int J Eat Disord. 2020. doi:10.1002/eat.23318

46. Cooper M, Reilly EE, Siegel JA, Coniglio K, Sadeh-Sharvit S, Pisetsky E, et al. Eating disorders during the COVID-19 pandemic: An overview of risks and recommendations for treatment and early intervention 2020. doi:10.31234/osf.io/x7hea.

47. Touyz S, Lacey H, Hay P. Eating disorders in the time of COVID-19. Journal of eating disorders. 2020;8:19; doi:10.1186/s40337-020-00295-3

48. Cherubini V, Skrami E, lannilli A, Cesaretti A, Paparusso AM, Alessandrelli MC, et al. Disordered eating behaviors in adolescents with type 1 diabetes: A cross-sectional population-based study in Italy. Int J Eat Disord. 2018;51(8):890-898; doi:10.1002/eat.22889

49. Pinna F, Diana E, Sanna L, et al. Assessment of eating disorders with the diabetes eating problems survey - revised (DEPS-R) in a representative sample of insulin-treated diabetic patients: a validation study in Italy. BMC Psychiatry. 2017;17(1):262. Published 2017 Jul 19; doi:10.1186/s12888-017-1434-8

50. Troncone A, Prisco F, Cascella C, Chianese A, Zanfardino A, lafusco D. The evaluation of body image in children with type 1 diabetes: A case-control study. J Health Psychol. 2016;21(4):493-504; doi:10.1177/1359105314529682

50. Troncone A, Cascella C, Chianese A, et al. Changes in body image and onset of disordered eating behaviors in youth with type 1 diabetes over a five-year longitudinal follow-up. J Psychosom Res. 2018;109:44-50: doi:10.1016/j.jpsychores.2018.03.169

51. Troncone A, Chianese A, Zanfardino A, Cascella C, Confetto S, Piscopo A, et al. Disordered Eating Behaviors Among Italian Adolescents with Type 1 Diabetes: Exploring Relationships with Parents' Eating Disorder Symptoms, Externalizing and Internalizing Behaviors, and Body Image Problems. J Clin Psychol Med Settings. 2019. doi:10.1007/s10880-019-09665-9 
52. Wang Y, Xu B, Zhao G, Cao R, He X, Fu S. Is quarantine related to immediate negative psychological consequences during the 2009 H1N1 epidemic?. Gen Hosp Psychiatry. 2011;33(1):75-77; doi:10.1016/j.genhosppsych.2010.11.001

53. Markowitz JT, Butler DA, Volkening LK, Antisdel JE, Anderson BJ, Laffel, LMB. (2010). Brief screening tool for disordered eating in diabetes: Internal consistency and external validity in a contemporary sample of pediatric patients with type 1 diabetes. Diabetes Care. 2010;33:495-500; doi:10.2337/dc09-1890

54. Scheuing N, Bartus B, Berger G, Haberland H, Icks A, Knauth B, et al. Clinical characteristics and outcome of 467 patients with a clinically recognized eating disorder identified among 52,215 patients with type 1 diabetes: a multicenter german/austrian study. Diabetes Care. 2014;37(6):1581-1589; doi:10.2337/dc13-2156

55. Howe CJ, Jawad AF, Kelly SD, Lipman TH. Weight-related concerns and behaviors in children and adolescents with type 1 diabetes. J Am Psychiatr Nurses Assoc. 2008;13(6):376-385; doi:10.1177/1078390307310154

56. Neumark-Sztainer D, Story M, Resnick MD, Garwick A, Blum RW. Body dissatisfaction and unhealthy weight-control practices among adolescents with and without chronic illness: a population-based study. Arch Pediatr Adolesc Med. 1995;149(12):1330-1335; doi:10.1001/archpedi.1995.02170250036005

57. Palladino DK, Helgeson VS. Friends or foes? A review of peer influence on self-care and glycemic control in adolescents with type 1 diabetes. $J$ Pediatr Psychol. 2012;37(5):591-603; doi:10.1093/jpepsy/jss009

58. American Diabetes Association (2020). 13. Children and Adolescents: Standards of Medical Care in Diabetes-2020. Diabetes care. 2020. 43(1): S163S182; doi:10.2337/dc20-S013

59. Clements MA, Foster NC, Maahs DM, Schatz DA, Olson BA, Tsalikian E, et al. Hemoglobin A1c (HbA1c) changes over time among adolescent and young adult participants in the T1D exchange clinic registry. Pediatr Diabetes. 2016;17(5):327-336; doi:10.1111/pedi.12295

60. National Paediatric Diabetes Audit Report 2016-2017: Care processes and outcomes. https ://www.rcpch .ac.uk/sites /defau It/files /201807/npda_annua I_repor t_2016_-_2017_april 2018_final updated_3.pdf (2018). Accessed 15 May 2020.

61. Colton PA, Olmsted MP, Daneman D, Rydall AC, Rodin GM. Natural history and predictors of disturbed eating behaviour in girls with Type 1 diabetes. Diabet Med. 2007;24(4):424-429; doi:10.1111/j.1464-5491.2007.02099.x

62. Tse J, Nansel TR, Haynie DL, Mehta SN, Laffel LM. Disordered eating behaviors are associated with poorer diet quality in adolescents with type 1 diabetes. J Acad Nutr Diet. 2012;112(11):1810-1814; doi:10.1016/j.jand.2012.06.359

63. Wisting L, Frøisland DH, Skrivarhaug T, Dahl-Jørgensen K, Rø O. Disturbed eating behavior and omission of insulin in adolescents receiving intensified insulin treatment: a nationwide population-based study. Diabetes Care. 2013;36(11):3382-3387; doi:10.2337/dc13-0431

64. Croll J, Neumark-Sztainer D, Story M, Ireland M. Prevalence and risk and protective factors related to disordered eating behaviors among adolescents: relationship to gender and ethnicity. J Adolesc Health. 2002;31(2):166-175;doi:10.1016/s1054-139x(02)00368-3

65. Neumark-Sztainer D, Wall M, Larson NI, Eisenberg ME, Loth K. Dieting and disordered eating behaviors from adolescence to young adulthood: findings from a 10-year longitudinal study. J Am Diet Assoc. 2011;111(7):1004-1011; doi:10.1016/j.jada.2011.04.012

66. Baechle C, Castillo K, Straßburger K, Stahl-Pehe A, Meissner T, Holl RW., et al. Is disordered eating behavior more prevalent in adolescents with early-onset type 1 diabetes than in their representative peers?. Int J Eat Disord. 2014;47(4):342-352; doi:10.1002/eat.22238

67. Colton PA, Olmsted MP, Daneman D, Farquhar JC, Wong H, Muskat S, et al. Eating Disorders in Girls and Women With Type 1 Diabetes: A Longitudinal Study of Prevalence, Onset, Remission, and Recurrence. Diabetes care 2015;38(7):1212-1217; doi:10.2337/dc14-2646

68. Stice E, Killen JD, Hayward C, Taylor CB. Age of onset for binge eating and purging during late adolescence: a 4-year survival analysis. J Abnorm Psychol. 1998;107(4):671-675; doi:10.1037//0021-843x.107.4.671

69. Pisetsky EM, Chao YM, Dierker LC, May AM, Striegel-Moore RH. Disordered eating and substance use in high-school students: results from the Youth Risk Behavior Surveillance System. Int J Eat Disord. 2008;41(5):464-470; doi:10.1002/eat.20520

70. Jenkins S, Horner SD. Barriers that influence eating behaviors in adolescents. J Pediatr Nurs. 2005;20(4):258-267; doi:10.1016/j.pedn.2005.02.014

71. Neumark-Sztainer D, Wall MM, Story M, Perry CL. Correlates of unhealthy weight-control behaviors among adolescents: implications for prevention programs. Health Psychol. 2003;22(1):88-98; doi:10.1037//0278-6133.22.1.88

72. Schleyer TK, Forrest JL. Methods for the design and administration of web-based surveys. J Am Med Inform Assoc. 2000;7(4):416-425; doi:10.1136/jamia.2000.0070416

73. Young-Hyman D, de Groot M, Hill-Briggs F, Gonzalez JS, Hood K, Peyrot M. Psychosocial Care for People With Diabetes: A Position Statement of the American Diabetes Association. Diabetes Care. 2016;39(12):2126-2140; doi:10.2337/dc16-2053 